\title{
Effects of climate change on growth criteria and yield of sunflower and chickpea crops in Iran
}

\author{
A. Koocheki ${ }^{1}$, M. Nassiri ${ }^{1}$, A. Soltani ${ }^{2}$, H. Sharifi ${ }^{3}$, R. Ghorbani ${ }^{1, *}$ \\ ${ }^{1}$ Department of Agronomy, Faculty of Agriculture, Ferdowsi University, Mashhad, PO Box: 91775-1163, Iran \\ ${ }^{2}$ Gorgan Agricultural University, Gorgan, Iran \\ ${ }^{3}$ Agricutural Research Organization, Karaj, Iran
}

\begin{abstract}
Yield and growth criteria of irrigated and rainfed sunflower Helianthus annus and chickpea Cicer arientinum were studied under simulated climate change for Tabriz in Iran. Monthly average temperature and rainfall under doubling $\mathrm{CO}_{2}$ were predicted using Goddard Institute for Space Studies (GISS) and Geophysical Fluid Dynamics Laboratory (GFDL) models. The effects of climatic change on crop growth period, yield components and water requirements of those crops were evaluated by a crop simulation model (OSBOL). Based on GISS and GFDL predictions, with doubling $\mathrm{CO}_{2}$ concentration, mean annual temperature for Tabriz increased by 4.6 and $4.3^{\circ} \mathrm{C}$, respectively. The results obtained by GISS showed that doubling $\mathrm{CO}_{2}$ will lead to an increase in mean temperature of $3.7^{\circ} \mathrm{C}$, and a $40 \%$ increase in mean rainfall, during the first 5 mo of the year. However, GFDL predicted an increase of $4.7^{\circ} \mathrm{C}$ in mean temperature and a reduction of $12 \%$ in mean rainfall during the first 5 mo of the year. According to OSBOL under GDFL predictions, the period from sowing to maturity and harvest index were reduced by climate change, whereas yield, biomass and water requirement for irrigated sunflower were increased. The biomass for rainfed sunflower increased, while days to maturity and harvest index were reduced. Yield predictions of OSBOL based on GISS contrasted with those based on GFDL. Doubling $\mathrm{CO}_{2}$ caused a reduction in days to maturity, biomass, yield and water requirements for irrigated chick pea. The number of days to maturity for rainfed chickpea was reduced and harvest index, biomass and yield were increased due to climate change.
\end{abstract}

KEY WORDS: Climate change $\cdot$ Crop productivity $\cdot$ Dry matter $\cdot$ Environment $\cdot$ Rainfall $\cdot$ Simulation . Yield

\section{INTRODUCTION}

The impacts of climate change on agriculture are likely to result from the effects of rising $\mathrm{CO}_{2}$ on plant growth, warmer and drier conditions, changes in wind speed, insect and plant disease pressures, and many more subtle changes resulting from altered interactions among components of crop agro-ecosystems (Smith \& Almaraz 2004); however, those impacts which cause losses in crop yield have generally been ignored (Lim et al. 2004, Scherm 2004). Increasing $\mathrm{CO}_{2}$ and other greenhouse gases are likely to have serious implications for global climate systems and to cause a series of novel environmental changes, predominantly through anthropogenic activities (Allen 1990, IPCC
2001, McMichael 2001, Centritto \& Loreto 2005). Increasing $\mathrm{CO}_{2}$, and consequently temperature, is likely to differentially affect all aspects of plant growth, development and function (Centritto \& Loreto 2005) differently according to the plant species and geographical location. Major effects of elevated atmospheric $\mathrm{CO}_{2}$ concentrations are the enhancement of $\mathrm{CO}_{2}$ diffusion into leaves and an increase in the rate of photosynthesis, especially in $\mathrm{C}_{3}$ plants, over a wide range of radiation intensities, and despite decreasing stomatal conductance (Lawlor \& Mitchell 1991). Elevated $\mathrm{CO}_{2}$ and temperatures affect plant growth and the water balance in a complex way, sometimes compensating for drought, sometimes aggravating it (Kimball et al. 2002). 
In general, $\mathrm{C}_{3}$ species can benefit more by the rise in $\mathrm{CO}_{2}$ in terms of carbon and water balance under well-watered conditions, while $\mathrm{C}_{4}$ species can benefit from drier environments (Jarvis et al. 1999). Although increase in atmospheric $\mathrm{CO}_{2}$ may improve plant water use efficiency (WUE), reduced precipitation and increased evapotranspiration losses negatively affect the availability of water for irrigation practices, and ongoing climatic changes could result in a drier environment in semi-arid regions such as Iran. A reduction in water availability would negatively affect crop production even in drought tolerant species. Plant response to a future drier environment with high levels of $\mathrm{CO}_{2}$ concentration will depend on the balance between the benefits obtained by increased WUE and the real extent of drought (Chartzoulakis \& Psarras 2005). Despite contradictory results on the effect of elevated $\mathrm{CO}_{2}$ on plant respiration, it is clear that the future increase of temperature will enhance carbon losses from respiration/ photorespiration which could have an adverse effect on crop production through net photosynthesis (Taiz \& Zeiger 1991).

Curry et al. (1990) simulated the effects of climate change on corn and soybean for the SE USA and found that yield of these crops under rainfed conditions was reduced by $50 \%$ due to climate change. Under irrigated conditions, however, yield of corn was reduced by $20 \%$ and that of soybean increased by $14 \%$. In the same simulation, it was concluded that water requirements for both crops was increased. Sinclair \& Rawlins (1993) also found that yield of corn was not sensitive to climate change, while climate change had a significant positive effect on soybean yield. The contradictory results seem to be due to the wide range of models used by different authors and also diverse climatic conditions under which the models were tested.

Climate change in developing countries is expected to cause health problems and problems of access to adequate food, clean water and other resources, and thereby climate could be a vital factor (Pachauri 2004). Productivity of agricultural systems in Iran is very sensitive to interannual variations in environmental factors, because the ecophysiological factors affecting crop production are not generally very suitable for plant growth and development in most of the country. Crop yield in Iran varies from year to year, largely as a result of highly variable weather conditions, and therefore there is an increasing concern about changes in climate and the combined effects of these changes on crop production. To address this concern, several studies were carried out to predict the potential impacts of climate change on crop production in different areas of Iran. The purpose of the present study was to investigate the effects on climatic factors of doubling $\mathrm{CO}_{2}$ concentration, and its consequences on the growth and development of sunflower and chickpea under irrigated and rainfed conditions.

\section{MATERIALS AND METHODS}

General Circulation Models (GCMs) are the most reliable means of predicting climate changes (Curry et al. 1990, Matthews et al. 1994, Schmidt et al. 2004). Two GCMs including the Goddard Institute for Space Studies model (GISS; Russell et al. 1995) and the Geophysical Fluid Dynamics Laboratory model (GFDL; Manabe et al. 1991, 1992) were used to simulate changes in temperature, rainfall, radiation and presumed doubling $\mathrm{CO}_{2}$ concentration.

The observed data along with the data predicted by GISS and GFDL were used to study the effects of climate changes on growth and development of sunflower and chickpea. Therefore, 3 series of data were obtained: (1) long term observed data, (2) predicted data based on GISS and (3) predicted data based on GFDL. Coefficients obtained from these models were applied to a mean of 30 yr climatic data (1965-1995) for the Tabriz area of Iran.

Direct output from GCMs is inadequate for regional scale impact analysis due to the coarse spatial resolution of GCMs. To overcome these difficulties and to provide useful local or regional scale climate scenarios for impact modeling, techniques such as pattern scaling, regional climate models (RCMs), and statistical downscaling have been proposed. Statistical downscaling was the technique adopted for this study. This method seeks to establish empirical relationships between observed large-scale variables, such as atmospheric pressure or geopotential heights, and an observed climate time series, such as temperature, precipitation or radiation. The use of variables for the upper layers of the atmosphere is based on the assumption that GCMs simulate upper air variables more accurately than surface variables (such as precipitation) resolved by large GCM grid sizes (Wilby \& Wigley 2000). As a consequence, the relationships between upper air and surface variables provide transfer functions which can then be applied to output data from GCMs for future time periods (Karl et al. 1990). On this basis, future climate scenarios can be generated at a regional scale, while it is assumed that the derived relationships will remain stable under climate change conditions. Using this method, the reanalyzed data was regridded to the GCM output grid resolution. Climate change scenarios were adapted from IPCC IS95a emission scenario (IPCC 2001). This involves a $1 \%$ $\mathrm{yr}^{-1}$ rise in radiative forcing, but no consideration of tropospheric ozone, with doubling $\mathrm{CO}_{2}$ concentration by 2100 . This scenario has been deemed suitable for prediction of climate change impacts on Iranian agriculture (Koocheki et al. 2003). The resulting datasets were then used to generate climate scenar- 
ios for 2 different periods: 1965-1995 (baseline), and 2065-2095 (2080). The difference between the modeled-future (2080) and modeled-current (baseline) scenarios was calculated and added to the baseline observations to estimate a future climate scenario. Application of statistical downscaling of GCM predictions in Iran used in this study is described in detail by Koocheki et al. (in press).

We evaluated the effects that change in climatic parameters have on growth and development of sunflower and chickpea under climate conditions of Tabriz. For this purpose a simplified model (OSBOL) was developed (Koocheki et al. 1999). This model is based on the following principles:

Phenological development. To quantify crop development, heat period concept was used. In the model the accumulated daily heat period was calculated for each simulated day as follows:

$$
\begin{array}{ll}
\text { DTT }=0 & \text { T }<\text { TB } \\
\text { DTT }=\text { T }- \text { TB } & \text { TB }<\text { T }<\text { TO } \\
\text { DTT }=\text { T }- \text { TO } & \text { TO }<\text { T }
\end{array}
$$

where DTT is daily heat period in terms of degree days, $\mathrm{T}$ is mean daily temperature, TB is base temperature for crop development, and TO is optimal temperature for plant development. Crop development stages were described by a dimensionless variable (DVS) which has the value 0 at seedling emergence, 1 at flowering and 2 at maturity. DVS is obtained by integration of developmental rate (DVR, $\mathrm{d}^{-1}$ ). DVR is the reciprocal of the required length of each given stage of development and it is calculated for flowering in sunflower and chickpea as follows:

$$
\mathrm{DVR}=\mathrm{DTT} / \mathrm{TTEE}
$$

where TTEE is required heat period from emergence to flowering. However, after flowering DVR is calculated as follows:

$$
\text { DVR }=\text { DTT } /(\text { TTME }- \text { TTEE })
$$

where TTME is heat period requirement from emergence to maturity. DVR is corrected for moisture deficit.

Leaf area. In the initial stages of growth, heat is the main determinant of leaf expansion and providing there is no moisture limitation, leaf area grows exponentially with heat accumulation and can be calculated using the following formula:

$$
\mathrm{LAI}=\mathrm{PDEN} \times \mathrm{LAO} \times \mathrm{EXP}(\mathrm{RLER} \times \mathrm{TT})
$$

where LAI is leaf area index, PDEN is plant density (ind. $\mathrm{m}^{-2}$ ), LAO is seedling leaf area at the time of emergence, and TT is heat period.
After the end of the exponential stage, leaf area growth rate is reduced (due to shading and inadequate photosynthesis). Daily leaf expansion rate (GLAI) is calculated by:

$$
\mathrm{GLAI}=\mathrm{LFGR} / \mathrm{SLW}
$$

where LFGR is the dry matter allocated to leaves $\left(\mathrm{g} \mathrm{m}^{-2}\right.$ $\left.\mathrm{d}^{-1}\right)$ and SLW is specific leaf weight $\left(\mathrm{g} \mathrm{m}^{-2}\right)$.

To calculate the rate of leaf senescence, a parameter for senescence (LDR) was used which was a function of temperature, shading and moisture stress. For a given day, the amount of LAI lost (DLAI) is calculated by:

$$
\mathrm{DLAI}=\mathrm{LAI} \times \mathrm{LDR}
$$

Dry matter production and allocation. Daily dry matter produced is the product of photosynthetically active radiation $\left(\mathrm{PAR}, \mathrm{MJ} \mathrm{m}^{-2}\right)$ and radiation use efficiency (RUE, $\mathrm{g} \mathrm{MJ}^{-1}$ ).

$$
\begin{gathered}
\mathrm{IPAR}=\mathrm{PAR} \times\left(1-\mathrm{e}^{(-\mathrm{K} \times \mathrm{LAI})}\right) \\
\mathrm{DBP}=\mathrm{IPAR} \times \mathrm{RUE}
\end{gathered}
$$

where IPAR is intercepted photosynthetically active radiation, $\mathrm{K}$ is the extinction coefficient for PAR and DBP is daily biomass produced. RUE is corrected for development stage and for heat and water stress. DBP is allocated to plant parts such as leaves, stem and harvestable yield. The partition coefficient is a function of developmental stage and water stress. Repartitioning of dry matter from vegetative organs to storage organs was simulated based on the assumption that, at the time of filling of storage organs, the part of the stem biomass which is composed of nonstructural compounds is allocated to these organs.

Soil water balance. Soil is usually assumed to consist of 2 layers, the upper part having a depth of around $20 \mathrm{~cm}$. At the time of seedling emergence the depth of the lower layer is equal to that of the upper layer, but after seedling emergence and root elongation this depth increases. For a given day, the amount of water in the upper and the lower layer is calculated by:

$$
\begin{aligned}
& \operatorname{ESW}(\mathrm{t})=\mathrm{ESW}(\mathrm{t}-1)+\mathrm{IRGW}-\mathrm{E}-\mathrm{TRI}-\mathrm{D} \\
& \operatorname{ATSW}(\mathrm{t})= \\
& \operatorname{ATSW}(\mathrm{t}-1)+\mathrm{I}+\mathrm{IRGW}+\mathrm{NEWAT}-\mathrm{E}-\mathrm{TR}-\mathrm{D}
\end{aligned}
$$

where ESW is the amount of water extracted from the upper layer, I is the amount of water infiltrated, IRGW is the amount of irrigated water, E is the evaporation, TRI is the part of the upper layer soil water lost through transpiration, TR is the total transpiration, ATSW is the amount of water in soil subjected to transpiration, NEWAT is the amount of water which has been infiltrated due to facilitation through root proliferation and $\mathrm{D}$ is the amount of water lost to deeper soil layers. 


\section{RESULTS AND DISCUSSION}

\subsection{Effect of doubling $\mathrm{CO}_{2}$ on temperature and rainfall in Iran}

Since GFDL performed more effectively than GISS over the whole country, the former model was used. The predicted results for temperature and rainfall in different locations of Iran are presented in Table 1. The temperature rise varied between $3.8^{\circ} \mathrm{C}$ for BandarAbbas in the south of Iran and $4.3^{\circ} \mathrm{C}$ for Orumiah in the northwest. These places are located in 2 climate extremes, and yet the difference in predicted temperatures was only $0.5^{\circ} \mathrm{C}$. In most of the locations, the predicted temperature rise was $>4^{\circ} \mathrm{C}$, which is in an acceptable range for the country. Changes in rainfall predicted with a doubling of $\mathrm{CO}_{2}$ were between $-0.2 \%$ in the north (Ardabil) and $14.6 \%$ in central and SE Iran (Arak and Zahedan, respectively). Ardabil was the only location where a rainfall increase was not expected.

\subsection{Estimate of climate changes in Tabriz}

Prediction for Tabriz was made on a monthly basis by using GISS and GFDL (Table 2, Fig. 1). With dou-
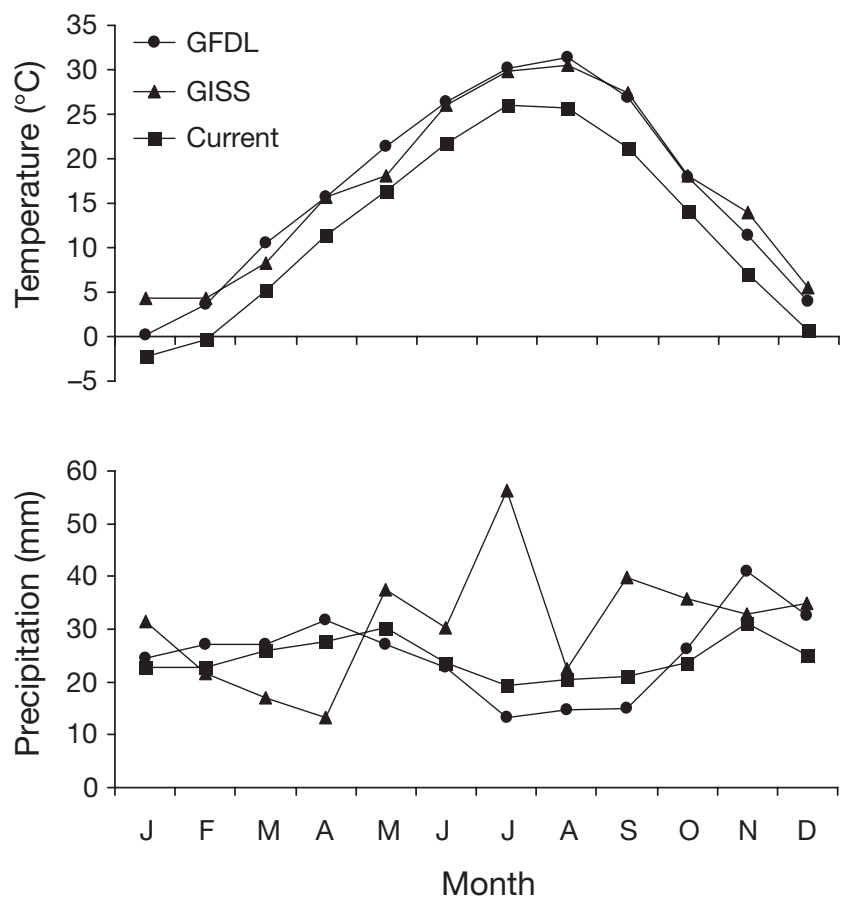

Fig. 1. Effect of doubling $\mathrm{CO}_{2}$ concentration on mean annual temperature and rainfall using Goddard Institute for Space Studies (GISS) and Geophysical Fluid Dynamics Laboratory (GFDL) models for Tabriz
Table 1. Effect of doubling $\mathrm{CO}_{2}$ concentration on mean annual temperature and rainfall in different areas of Iran (predicted by Geophysical Fluid Dynamics Laboratory model [GFDL])

\begin{tabular}{|c|c|c|}
\hline City & $\Delta$ temperature $\left({ }^{\circ} \mathrm{C}\right)$ & $\Delta$ rainfall $(\%)$ \\
\hline Arak & 4.2 & 14.6 \\
\hline Ardabil & 4.2 & -0.2 \\
\hline Orumiah & 4.3 & 0.9 \\
\hline Isfahan & 4.3 & 13.9 \\
\hline Ahvaz & 4.1 & 1.9 \\
\hline Ilam & 4.2 & 11.3 \\
\hline Bandar-e Abbas & 3.8 & 9.8 \\
\hline Bushehr & 4.4 & 7.6 \\
\hline Tabriz & 4.3 & 1.1 \\
\hline Tehran & 4.2 & 12.6 \\
\hline Khorram Abad & 4.2 & 13.6 \\
\hline Rasht & 4.2 & 3.4 \\
\hline Zahedan & 3.9 & 14.6 \\
\hline Zanjan & 4.2 & 5.3 \\
\hline Semnan & 4.2 & 14.1 \\
\hline Sanandaj & 4.2 & 8.4 \\
\hline Sari & 4.1 & 11.5 \\
\hline Shahr-e-kord & 4.3 & 14.1 \\
\hline Shiraz & 4.1 & 10.0 \\
\hline Kerman & 4.1 & 14.2 \\
\hline Kermanshah & 4.2 & 13.0 \\
\hline Gorgan & 4.1 & 10.2 \\
\hline Mashhad & 4.1 & 12.8 \\
\hline Hamadan & 4.2 & 11.7 \\
\hline Yasouj & 4.2 & 10.9 \\
\hline Yazd & 4.3 & 13.3 \\
\hline
\end{tabular}

bling $\mathrm{CO}_{2}$ concentration, mean annual temperature for Tabriz was predicted to increase by 4.6 and $4.3^{\circ} \mathrm{C}$, based on GISS and GFDL, respectively. Temperature increase varied according to season, and depended on the model used. Predictions made by GISS showed a temperature increase in the autumn and winter, whereas GFDL predicted a temperature increase during spring and summer. Temperatures in the first $5 \mathrm{mo}$ of the growing season (April to August) were predicted to increase by 3.7 and $4.7^{\circ} \mathrm{C}$ based on GISS and GFDL, respectively.

Predictions of rainfall change were 32 and $1 \%$, for GISS and GFDL, respectively. GISS predicted an increase in the amount of rainfall with a more consistent distribution in spring and summer, whereas GFDL predicted no changes in the amount of rainfall, but rather a change in the pattern of rainfall in spring and summer. Since sowing date for rainfed crops in this area coincides with the beginning of spring, the prediction of GFDL indicated an increase in the soil moisture level, but at the same time the effectiveness of rainfall is less than in autumn. A 48 and $8 \%$ decrease in rainfall (based on GISS and GFDL, respectively) were predicted for the first 4 mo of the growing period 
(April to July); while rainfall in the 6 mo prior to planting was predicted to increase by 16 and $17 \%$ (GISS and GFDL, respectively).

\subsection{Effects of climate change on growth criteria under irrigated conditions}

Doubling of the $\mathrm{CO}_{2}$ concentration caused a reduction in growth period for sunflower and chickpea (Table 3). These reductions were about 14 and $18 \%$ (GISS and GFDL, respectively) for sunflower and 8 and $12 \%$ (GISS and GFDL, respectively) for chickpea. Since temperature is the main determinant of the length of growth period, the reduction in growth period predicted by the models could be attributed to increase in temperature. Lower LAI in chickpea might be due to the direct effect of increasing $\mathrm{CO}_{2}$ or its indirect effects through changes in temperature and rainfall. However, these results were not observed for sunflower. This contradictory result could be attributed to different canopy criteria of these crops. Sunflower has a thermophilous habit helix arrangement and it can continue to expand its leaves even in the predicted climatic conditions. It is also thought to increase its rate of photosynthesis in response to rising $\mathrm{CO}_{2}$ (Allen 1990, Kimball \& Idso 1983). Crop growth rate (CGR) for chickpea was changed by -5 and $1 \%$ (GISS and GFDL, respectively). These values were 52 and $63 \%$ for sunflower. This could also be associated with the growth criteria of sunflower and particularly LAI mentioned earlier.

Climate change reduced the biological yield of chickpea, while increasing it in sunflower. Since biological yield is a function of interactive effects of growth period and $C G R$, reduction in biological yield due to stable CGR and climate-change-related reduction in growth period is justified. In sunflower the magnitude of increase in CGR is very high, which could compensate for the reduction of growth period and also increase biological yield. Economic yield of these crops showed the same trend as biological yield. Economic yield showed a reduction of 13 and $8 \%$ for chickpea and an increase of 16 and $24 \%$ for sunflower predicted by GISS and GFDL, respectively (Table 3).

\subsection{Effects of climate change on growth criteria under rainfed conditions}

Doubling $\mathrm{CO}_{2}$ concentration and its consequences with regard to temperature reduced the maturation period of both crops under rainfed conditions (Table 4). LAI showed the same pattern of changes as under irrigated conditions. However, under rainfed conditions, the reduction in LAI for chickpea was smaller and the increase for sunflower was higher than for irrigated conditions. This could be attributed to the shorter growth period under rainfed conditions (approximately $20 \mathrm{~d}$ less), and therefore more favorable conditions for the expansion of leaves during growing seasons. Positive effects of climate change for both species under rainfed, as compared to irrigated, crops were more pronounced for photosynthesis than LAI. The magnitude of increase in CGR predicted by GISS and GFDL were 34 and $46 \%$ for chickpea and 54 and $91 \%$ for sunflower, respectively (Table 4). Since the

Table 2. Effect of doubling $\mathrm{CO}_{2}$ concentration on mean annual temperature and rainfall using Goddard Institute for Space Studies (GISS) and GFDL models for Tabriz

\begin{tabular}{|lrrrrrr|}
\hline \multirow{2}{*}{ Month } & \multicolumn{3}{c}{$\Delta$ temperature $\left({ }^{\circ} \mathrm{C}\right)$} & \multicolumn{3}{c|}{$\Delta$ rainfall $(\mathrm{mm})$} \\
& Current & GISS & GFDL & Current & GISS & GFDL \\
\hline 1 & -2.2 & 4.2 & 0.1 & 22.7 & 31.4 & 24.5 \\
2 & -0.3 & 4.2 & 3.5 & 22.7 & 21.6 & 27.1 \\
3 & 5.0 & 8.3 & 10.4 & 26.0 & 16.9 & 27.0 \\
4 & 11.4 & 15.6 & 15.6 & 27.7 & 13.3 & 31.6 \\
5 & 16.4 & 18.1 & 21.4 & 30.3 & 37.3 & 27.0 \\
6 & 21.8 & 25.9 & 26.4 & 23.7 & 30.3 & 22.7 \\
7 & 26.1 & 29.8 & 30.1 & 19.3 & 56.3 & 13.3 \\
8 & 25.6 & 30.4 & 31.4 & 20.5 & 22.5 & 14.5 \\
9 & 21.2 & 27.3 & 26.8 & 21.0 & 39.8 & 14.9 \\
10 & 14.1 & 18.1 & 17.9 & 23.6 & 35.9 & 26.2 \\
11 & 7.0 & 13.9 & 11.3 & 31.2 & 32.7 & 40.8 \\
12 & 0.7 & 5.4 & 4.0 & 24.9 & 34.9 & 32.4 \\
\hline
\end{tabular}

Table 3. Helianthus annus and Cicer arientinum. Effects of doubling $\mathrm{CO}_{2}$ on changes $(\%)$ in the crop criteria for irrigated chickpea and sunflower, predicted by GISS and GFDL. LAI: leaf area index; CGR: crop growth rate

\begin{tabular}{|lcrrrrr|}
\hline & \multicolumn{3}{c}{ Chickpea } & \multicolumn{3}{c|}{ Sunflower } \\
& Current & GISS & GFDL & Current & GISS & GFDL \\
\hline Days to maturity & 100 & 91.6 & 88.3 & 100 & 86.2 & 82.1 \\
LAI & 100 & 80.0 & 79.1 & 100 & 121.9 & 120.6 \\
CGR & 100 & 95.0 & 101.4 & 100 & 152.2 & 162.6 \\
Evapotranspiration & 100 & 79.4 & 18.5 & 100 & 102.7 & 103.9 \\
Irrigation required & 100 & 70.3 & 74.9 & 100 & 103.0 & 105.2 \\
Biological yield & 100 & 87.1 & 89.5 & 100 & 131.2 & 133.5 \\
Grain yield & 100 & 87.2 & 91.8 & 100 & 116.2 & 123.7 \\
Harvest index & 100 & 100 & 101.5 & 100 & 88.3 & 92.2 \\
\hline
\end{tabular}


increased percentage of CGR is more than the reduction in growth period, the biological yield would increase (see Table 4). Harvest index for chickpea was increased (for GISS and GFDL, respectively) by 21 and $47 \%$, while values for sunflower showed a reduction of 28 and $11 \%$ (Table 4 ). This reduction is probably due to unfavorable growth conditions during the seed filling period of sunflower. It can be concluded that climate change will affect crop growth and development, but the extent depends on many factors including crop species and water availability, i.e. the cropping system.

\section{CONCLUSIONS}

Climate change will not have a severe impact on yield of irrigated sunflower, but the negative effect for chickpea under irrigated conditions will be considerable.

For sunflower it can be concluded that: (1) sunflower under irrigation remains a viable crop in terms of yield under climate change; (2) impact of the change of annual temperature and precipitation on irrigated sunflower yield will not be a major problem because the shorter growing period will be compensated by higher CGR, (3) under rainfed conditions, in spite of higher CGR, harvestable yield of sunflower will be reduced due to reduction in harvest index.

For chickpea it can be concluded that: (1) irrigated chickpea crop will have a shorter growth period, reduced LAI and lower CGR from predicted climate change, leading to lower grain yield, (2) rainfed chickpea under doubling $\mathrm{CO}_{2}$ concentration will experience a higher CGR and higher biological yield which together with increased harvest index results in yield advantages.

\section{LITERATURE CITED}

Allen LH (1990) Plant response to rising carbon dioxide and potential interactions with air pollutants. J Environ Qual 19:15-34

Centritto M, Loreto F (2005) Photosynthesis in a changing world: photosynthesis and abiotic stresses. Agric Ecosyst Environ 106:115-117

Chartzoulakis K, Psarras G (2005) Global change effects on crop photosynthesis and production in Mediterranean: the case of Crete, Greece. Agric Ecosyst Environ 106: $147-157$

Curry RB, Peart RM, Jones JW, Boote KJ, Allen LH (1990) Simulation as a tool for analyzing crop response to climate change. Trans Am Soc Agric Eng 33:76-98

IPCC (Intergovernmental Panel on Climate Change) (2001)
Climate Change 2001: the scientific basis. IPCC Third Assessment Report, Geneva

Jarvis AJ, Mansfield TA, Davies WJ (1999) Stomatal behavior, photosynthesis and transpiration under rising $\mathrm{CO}_{2}$. Plant Cell Environ 22:639-648

Karl TR, Wang WC, Schlesinger ME, Knight RW, Portman D (1990) A method of relating general circulation model simulated climate to the observed local climate. Part I. Seasonal statistics. J Clim 3:1053-1079

Kimball BA, Idso SB (1983) Increasing atmospheric $\mathrm{CO}_{2}$ effects on crop yield, water use and climate. Agric Water Manag 7:35-72

Kimball BA, Kobayashi K, Bindi M (2002) Responses of agricultural crops to free-air $\mathrm{CO}_{2}$ enrichment. Adv Agron 77:293-368

Koocheki A, Soltani A, Sharifi R, Kamali GH (1999) Effects of climate change on growth, development and yield of irrigated and rainfed sunflower and chickpea under climatic condition of Tabriz. J Agric Sci Technol 15:45-54

Koocheki A, Nassiri M, Jamali G (2003) Weather conditions of Iran under climate change. Project Report. Iran Meteorological Organization, Tehran

Koocheki A, Nassiri M, Kamali GA, Shahandeh H (in press) Potential impacts of climate change on agro-meteorological indicators in Iran. Arid Land Res Manag

Lawlor DW, Mitchell RAC (1991) The effects of increasing $\mathrm{CO}_{2}$ on crop photosynthesis and productivity - a review of field studies. Plant Cell Environ 14:807-818

Lim C, Kafatos M, Megonigal P (2004) Correlation between atmospheric $\mathrm{CO}_{2}$ concentration and vegetation greenness in North America: $\mathrm{CO}_{2}$ fertilization effect. Clim Res 28:11-22

Manabe S, Stouffer RJ, Spelman MJ, Bryan K (1991) Transient response of a coupled ocean-atmosphere model to gradual changes of atmospheric $\mathrm{CO}_{2}$. Part I. Annual mean response. J Clim 4:785-818

Manabe S, Spelman MJ, Stouffer RJ (1992) Transient response of a coupled ocean-atmosphere model to gradual changes of atmospheric $\mathrm{CO}_{2}$. Part II. Seasonal response. J Clim 5:105-126

Matthews RB, Kropff MJ, Bachelet D (1994) General introduction. In: Matthews RB, Kropff MJ, Bachelet D, van Laar $\mathrm{HH}$ (eds) Modeling the impact of climate change on rice production in Asia. CAB International, Wallingford, p 3-7

McMichael AJ (2001) Impact of climatic and other environmental changes on food production and population health in coming decades. Proc Nutr Soc 60:195-201

Pachauri RK (2004) Climate and humanity. Global Environ Change 14:101-103 
Russell GL, Miller JR, Rind D (1995) A coupled atmosphereocean model for transient climate change studies. Atmos Ocean 33:683-730

Scherm H (2004) Climate change: can we predict the impacts on plant pathology and pest management? Can J Plant Pathol 26(3):267-273

Schmidt GA, Shindell DT, Miller RL, Mann ME, Rind D (2004) General circulation modelling of Holocene climate variability. Quat Sci Rev 23(20-22):2167-2181

Sinclair TR, Rawlins SL (1993) Inter-seasonal variation in soy-

Editorial responsibility: Otto Kinne,

Oldendorf/Luhe, Germany bean and maize yields under global environmental change. Agron J 85:406-409

Smith DL, Almaraz JJ (2004) Climate change and crop production: contributions, impacts, and adaptations. Can J Plant Pathol 26(3):253-266

Taiz L, Zeiger E (1991) Plant physiology. Benjamin/Cummings, Redwood City, CA

Wilby RL, Wigley TML (2000) Precipitation predictors for downscaling: observed and general circulation model relationships. Int J Climatol 20:641-661

Submitted: May 10, 2005; Accepted: February 27, 2006

Proofs received from author(s): April 8, 2006 